\title{
The orphan nuclear receptor small heterodimer partner is required for thiazolidinedione effects in leptin-deficient mice
}

\author{
Hsiu-Ting Tseng ${ }^{1}$, Young Joo Park², Yoon Kwang Lee ${ }^{3}$ and David D Moore ${ }^{1 *}$
}

\begin{abstract}
Background: Small heterodimer partner (SHP, NROB2) is involved in diverse metabolic pathways, including hepatic bile acid, lipid and glucose homeostasis, and has been implicated in effects on the peroxisome proliferator-activated receptor $\gamma$ (PPARY), a master regulator of adipogenesis and the receptor for antidiabetic drugs thiazolidinediones (TZDs). In this study, we aim to investigate the role of SHP in TZD response by comparing TZD-treated leptin-deficient (ob/ob) and leptin-, SHP-deficient (ob/ob;Shp ${ }^{-1-}$ ) double mutant mice.

Results: Both ob/ob and double mutant ob/ob;Shp ${ }^{-1-}$ mice developed hyperglycemia, insulin resistance, and hyperlipidemia, but hepatic fat accumulation was decreased in the double mutant ob/ob;Shp ${ }^{-1-}$ mice. PPARY2 mRNA levels were markedly lower in ob/ob;Shp ${ }^{-1-}$ liver and decreased to a lesser extent in adipose tissue. The TZD troglitazone did not reduce glucose or circulating triglyceride levels in ob/ob;Shp ${ }^{-1-}$ mice. Expression of the adipocytokines, such as adiponectin and resistin, was not stimulated by troglitazone treatment. Expression of hepatic lipogenic genes was also reduced in ob/ob:Shp ${ }^{-1-}$ mice. Moreover, overexpression of SHP by adenovirus infection increased PPARY2 mRNA levels in mouse primary hepatocytes.
\end{abstract}

Conclusions: Our results suggest that SHP is required for both antidiabetic and hypolipidemic effects of TZDs in ob/ob mice through regulation of PPARY expression.

Keywords: SHP, Troglitazone, PPARY, Thiazolidinedione

\section{Background}

Obesity is associated with cardiovascular disease, type 2 diabetes mellitus and some cancers [1,2]. Among these, type 2 diabetes mellitus is a major source of mortality in the obese population. Diabetes develops in the context of both insulin resistance and $\beta$ - cell dysfunction [3]. In insulin resistance, the ability of insulin to enhance glucose disposal in muscle and adipose tissue and to decrease gluconeogenesis in liver is impaired. Diabetes ensues when the pancreatic $\beta$-cell cannot compensate for insulin resistance by adequately increasing insulin secretion.

Thiazolidinediones (TZDs) are a class of antidiabetic drugs that act by increasing insulin sensitivity $[4,5]$. TZDs, including troglitazone, rosiglitazone and pioglitazone,

\footnotetext{
* Correspondence: moore@bcm.tmc.edu

'Department of Molecular and Cellular Biology, Baylor College of Medicine, One Baylor Plaza, Houston, Texas, USA

Full list of author information is available at the end of the article
}

improve insulin action in patients and a number of insulin-resistant obese and diabetic murine models, such as ob/ob (leptin-deficient), db/db (leptin receptordeficient), KKA ${ }^{\mathrm{y}}$ mice and Zucker fatty rats [6-8]. TZDs are potent agonist ligands for the nuclear hormone receptor peroxisome proliferator-activated receptor $\gamma$ (PPAR $\gamma$ ) and their antidiabetic actions are believed to be mediated by interactions with PPAR $\gamma$ $[9,10]$. PPAR $\gamma$ is a key regulator of adipogenesis $[11,12]$ that exists as two protein isoforms, PPAR $\gamma 1$ and $\gamma 2$, arising from differential promoter usage. PPAR $\gamma 2$ encodes 30 additional amino acids at the N-terminus compared to PPAR 1 1. PPAR 2 is expressed at highest levels in adipose tissue compared to other major insulin target tissues, such as liver and muscle, whereas PPAR 1 is expressed at relatively low levels in many tissues $[11,13]$. The expression pattern suggests that adipose tissue is the primary target of TZD-induced insulin sensitization as generally supported by tissue- 
specific PPAR $\gamma$ knockout studies, although other tissues and cell types also contribute [14-18]. PPARY expression levels can change under different physiological conditions and affect the response to TZD treatment [13]. For example, hepatic PPAR $\gamma$ expression is elevated in animals that develop fatty livers [18-20], and increased PPAR 2 expression is correlated with increased liver fat in human subjects with non-alcoholic fatty liver disease (NAFLD) [21]. TZD effects could be amplified in such PPAR $\gamma$-rich fatty livers, which may be particularly relevant for the beneficial effects of TZD treatment in human patients with non-alcoholic steatohepatitis (NASH) [22,23].

Mutations in the small heterodimer partner (SHP, NR0B2) have been associated with mild obesity in several human populations [24-27]. SHP is an atypical orphan nuclear receptor that lacks a conventional DNA-binding domain $[28,29]$. Although SHP interacts with several nuclear receptors by acting as a repressor [28,30-32], it has been reported to increase the transcriptional activation of PPARY [33]. In addition, hepatic PPAR $\gamma$ gene expression is upregulated in transgenic mice expressing SHP in the liver, suggesting that SHP may affect PPAR $\gamma$ expression at the transcription level [34].

To investigate the role of SHP in TZD response in obese diabetic mice, we compared glucose metabolism and lipid profiles in $o b / o b$ and $o b / o b ; S^{-/-}$double mutant mice after TZD treatment. Troglitazone did not reduce glucose or circulating triglyceride levels in the $o b / o b ; \operatorname{Sh}^{-1-}$ mice, which showed markedly decreased PPARy expression in liver and, to a lesser extent, adipose tissue. Furthermore, SHP overexpression increased PPAR $\gamma$ mRNA levels in primary hepatocytes. These results suggest that SHP is required for TZD effects in $o b / o b$ mice and for a potential indirect activation of PPAR gene.

\section{Methods}

\section{Animals and treatments}

$\mathrm{Shp}^{-1-}$ mice were generated previously in this laboratory with a mixed C57BL/129sv hybrid background [35]. They were backcrossed to C57BL/6 J mice for 10 generations to obtain $>99.99 \%$ pure C57BL/6 J background. The leptin-deficient $o b / o b$ and $o b / o b ; S h p^{-1-}$ mice were generated as described previously [36]. Groups of 10-15 male $o b / o b$ and $o b / o b ; S h p^{-1-}$ mice (7- to 8-week-old) were oral gavaged with vehicle $(10 \%$ dimethylsulfoxide (DMSO) in corn oil) or troglitazone (Cayman chemical, dissolved in DMSO, $10 \mathrm{mg} / \mathrm{kg} /$ day) for two weeks. Before the first day of treatment and on the day before sacrifice, mice were fasted overnight and blood samples were collected from the orbital plexus. Livers and white adipose tissue were dissected, weighed and fixed for histological analysis, or snap frozen in liquid nitrogen and stored at $-80^{\circ} \mathrm{C}$ until use. Mice were maintained in the accredited pathogen-free facility at Baylor College of Medicine on a 12-hour light/dark cycle and fed a standard rodent chow and water ad libitum. All protocols for animal use were approved by the animal care committee of Baylor College of Medicine.

\section{Histological analysis}

Livers were fixed, dehydrated and embedded in paraffin. Sections were cut with a thickness of $5 \mu \mathrm{m}$ and stained with Harris hematoxylin-eosin (Sigma).

\section{Serum and tissue chemistry}

Serum was prepared from whole blood and stored at $-80^{\circ} \mathrm{C}$ until use. Lipids were extracted from liver using chloroform-methanol extraction [37]. Enzymatic assay kits were used for the determination of non-esterified fatty acids (Wako), cholesterol and triglyceride (Thermo Electron). Insulin levels were measured by a mouse/rat insulin ELISA kit (Millipore-Linco).

\section{Glucose tolerance test}

Glucose tolerance tests (GTT) were performed by intraperitoneal injection of glucose $(2 \mathrm{~g} / \mathrm{kg}$ of body weight) following overnight fasting. Blood samples were taken at $0,15,30,60,120$ minutes from the tail vein and were analyzed for glucose concentrations using kits from Thermo Electron.

\section{RNA isolation and real-time quantitative PCR}

Total RNA was isolated using TRIzol reagent (Invitrogen). $1 \mu \mathrm{g}$ of total RNA was reverse transcribed using QuantiTect Reverse Transcription kit (Qiagen) according to manufacturer's instructions. Real-time quantitative PCR (SYBR green) analysis was performed on an ABI prism 7700 sequence detection system (Applied Biosystems) under factory default thermal cycling conditions $\left(50^{\circ} \mathrm{C}\right.$, $2 \mathrm{~min} ; 95^{\circ} \mathrm{C}, 10 \mathrm{~min}$; and 40 cycles at $95^{\circ} \mathrm{C}, 15 \mathrm{~s} ; 60^{\circ} \mathrm{C}$, $1 \mathrm{~min})$. Expression was normalized to $36 \mathrm{~B} 4$ and the relative quantification was calculated using $\Delta \Delta \mathrm{Ct}$ formula.

\section{Primary hepatocyte isolation, culture and adenoviral transduction}

Primary hepatocytes were prepared from 8- to 12-weekold wild type mice by in situ perfusion and single-step Percoll gradient centrifugation [35]. Cells were plated at $10^{6}$ per $6-\mathrm{cm}$ dish and grown in Williams' E medium supplemented with $10 \mu \mathrm{g} / \mathrm{ml}$ transferrin, $10 \mu \mathrm{g} / \mathrm{ml}$ insulin, $100 \mathrm{U} / \mathrm{ml}$ penicillin and $100 \mu \mathrm{g} / \mathrm{ml}$ streptomycin. One day after plating, the cells were infected with a SHP-expressing adenovirus or a control virus expressing GFP as described [38] for two hours at a multiplicity of infection (MOI) of 20. Virus-containing media were removed and cells were cultured for two days after infection. Total 
RNA were isolated from cells for real-time quantitative PCR analysis.

\section{Statistical analysis}

Values are presented as means \pm SEM. Statistical significance was determined by two-tailed $t$ test or ANOVA, as appropriate.

\section{Results}

Troglitazone does not improve the diabetic syndromes in ob/ob;Shp ${ }^{-1-}$ mice

The $o b / o b$ mouse is a valuable type 2 diabetes model. Based on the role of the orphan nuclear receptor SHP in metabolic pathways, we generated $o b / o b ; S h p^{-/-}$double mutant mice. The obesity of the double mutants was not different from the $o b / o b$ mice $\left(9-10\right.$-week-old $o b / o b ; S h p^{-1-}$ body weight $38.38 \pm 1.9 \mathrm{~g}$ versus $o b / o b 35.8 \pm 1.7 \mathrm{~g}$ ). We initially assessed the effects of SHP deficiency on glucose homeostasis by measuring blood glucose and insulin levels. Glucose levels of $o b / o b ; S h p^{-/-}$mice were significantly higher than those of $o b / o b$ mice, whereas the insulin level was markedly lower (Figure 1A, B). To further characterize

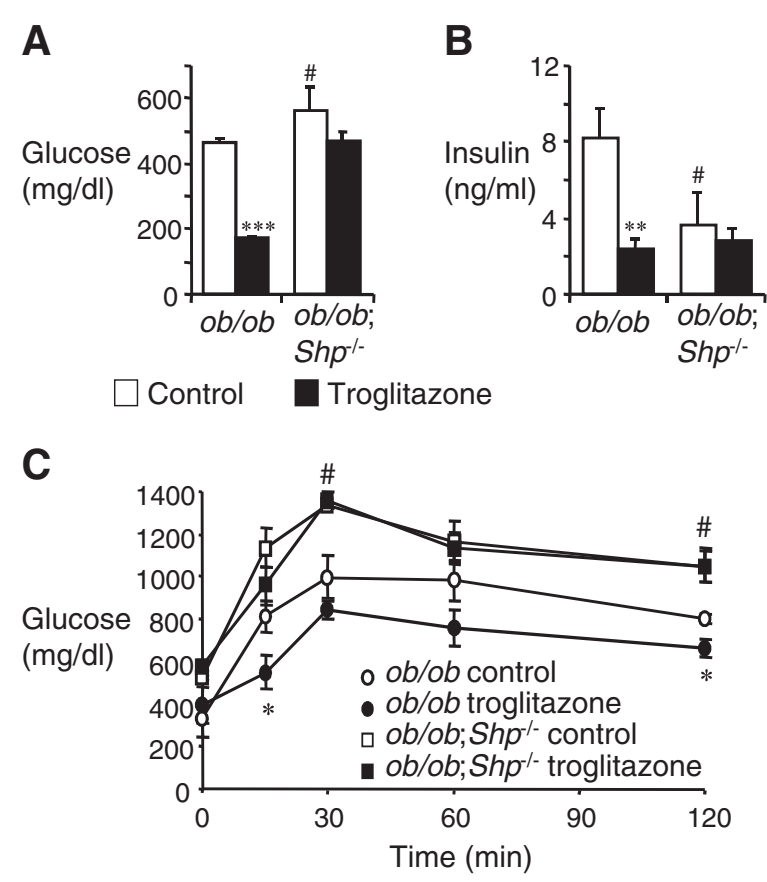

Figure 1 SHP deficiency causes non-responsiveness to antidiabetic effect of TZDs. (A, B) Serum glucose (A) and insulin (B) levels under fasting conditions. 7-8 week-old male ob/ob and ob/ob;Shp ${ }^{-1-}$ mice were treated with control (open bars) or troglitazone (filled bars) for 2 weeks. (C) Glucose tolerance tests. Intraperitoneal glucose tolerance tests were performed on ob/ob and ob/ob;Shp ${ }^{-1-}$ mice treated with control (open symbols) or troglitazone (filled symbols) for 2 weeks. $n=4-5$ per group. Data are mean $\pm S E M$. ${ }^{*} P<0.05$, ${ }^{*} P<0.01$, ${ }^{* * *} \mathrm{P}<0.001$ for differences between control and troglitazone-treated ob/ob mice. \#P $<0.01$ for differences between ob/ob;Shp ${ }^{-1-}$ (with no effect of troglitazone treatment) and control-treated $o b / o b$ mice. glucose metabolism, glucose tolerance tests were performed and $o b / o b ; S_{S p}{ }^{-1-}$ mice were more glucoseintolerant compared to $o b / o b$ mice (Figure 1C). These results suggest that SHP deficiency aggravates hyperglycemia and insulin resistance in $o b / o b$ mice, which is quite different from the improvements previously described [36]. The basis for this marked discrepancy is not clear.

To test whether TZDs are effective in $o b / o b ; S h p^{-1-}$ mice with severe glucose intolerance, both $o b / o b$ and $o b / o b ; S_{h} p^{-1-}$ mice were treated with troglitazone for 2 weeks. As expected, the $o b / o b$ mice showed dramatically lower serum glucose and insulin levels, as well as improved glucose tolerance (Figure 1). In contrast, neither the serum glucose and insulin levels nor the glucose tolerance was improved in the $o b / o b ; S h p^{-1-}$ mice. These results indicate that SHP is required for antidiabetic effects of TZDs in $o b / o b$ mice.

\section{Troglitazone has no effect on the lipid profile of $o b / o b ; S^{-1-}$ mice}

Since SHP is normally highly expressed in the liver, we further investigated the potential effects of SHP deficiency in the $o b / o b$ fatty liver. While the body weight showed no significant difference between $o b / o b$ and $o b /$ $o b ; S h p^{-/-}$mice, the liver weight of $o b / o b ; S h p^{-1-}$ mice was significantly lower than that of $o b / o b$ mice, resulting in a smaller liver/body weight ratio (9-10-week-old $o b / o b ;$ Shp $^{-1-}$ liver weight $1.67 \pm 0.17 \mathrm{~g}$ versus $o b / o b$ $2.12 \pm 0.18 \mathrm{~g}, \mathrm{P}<0.05)$ (Figure $2 \mathrm{~B}$ ). Histological analysis of the liver showed that lipid droplets were much smaller and less numerous in ob/ob;Shp ${ }^{-1-}$ mice than that in $o b / o b$ mice, indicating an improvement of fatty liver in $o b / o b ; \mathrm{Shp}^{-1-}$ mice (Figure 2A), and this was confirmed by measuring hepatic triglycerides (Figure 2C). These results are consistent with those described previously [36]. Troglitazone treatment of $o b / o b$ mice caused a significant increase in liver/body weight ratio and hepatic triglyceride content (Figure 2B and C). Histological results also revealed that the size and number of lipid droplets were increased by troglitazone treatment in $o b /$ $o b$ mice (Figure 2A). However, these effects of troglitazone were not observed in $o b / o b ; S_{S h}{ }^{-/-}$mice. In addition, the serum triglyceride- and FFA-lowering actions of troglitazone observed in the $o b / o b$ mice were absent in $o b /$ $o b ; S h p^{-1-}$ mice (Figure 2D and E). These results confirm that SHP is involved in the development of fatty liver in $o b / o b$ mice and is required for hypolipidemic effects of TZDs.

\section{SHP deficiency downregulates the expression of lipogenic} genes in $o b / o b$ mice liver

Since hepatic PPAR $\gamma$ has been reported to play a critical role in the development of fatty liver of $o b / o b$ mice [18], 


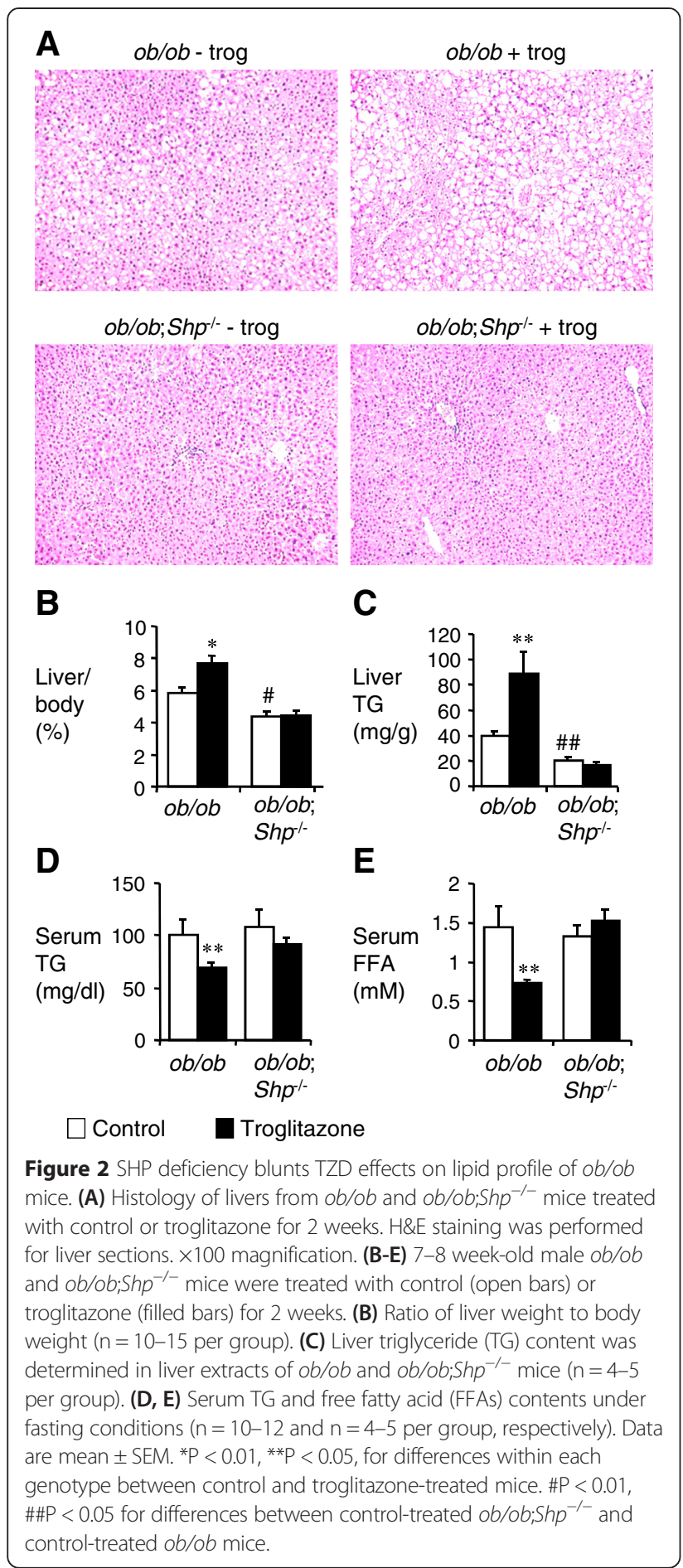

PPAR 1 and $\gamma 2$ expression was examined in $w t, \operatorname{Shp}^{-1-}, o b /$ $o b$ and $o b / o b ; S_{h} p^{-/-}$mice (Figure 3A). The low basal PPAR $\gamma 1$ levels showed about a 3-fold increase in both $o b /$ $o b$ and $o b / o b ; S h p^{-1-}$ mice compared to wt mice, but PPAR 2 levels exhibited dramatic differences between $o b /$ $o b$ and $o b / o b ; S h p^{-1-}$ mice: a 40-fold increase in $o b / o b$ mice

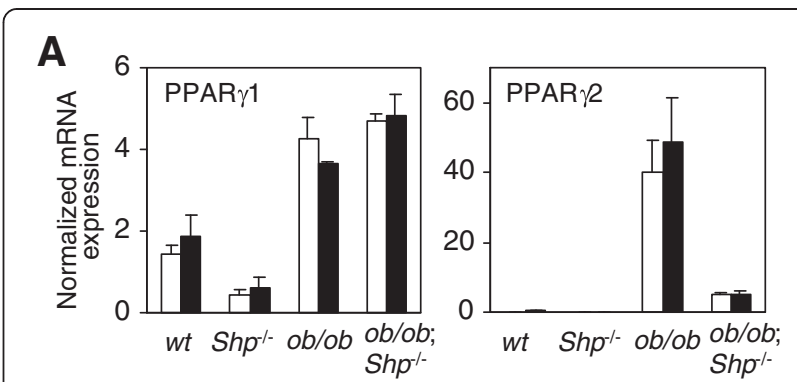

B
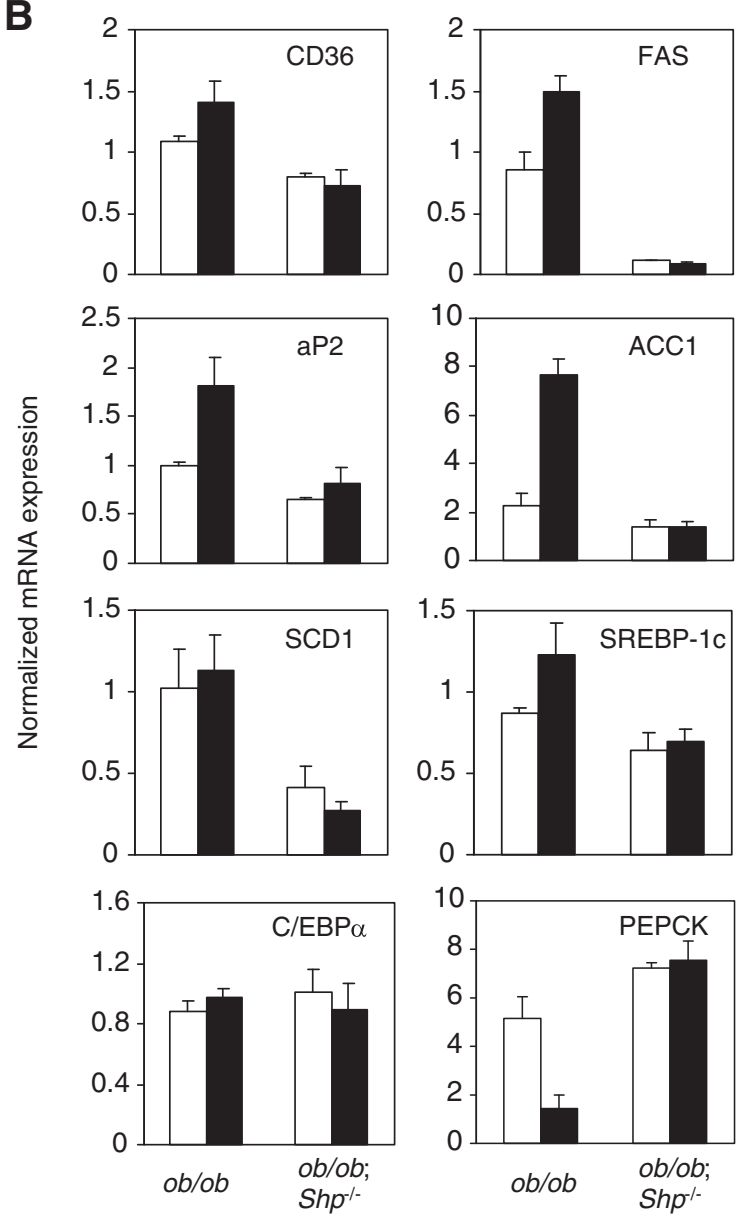

$\square$ Control

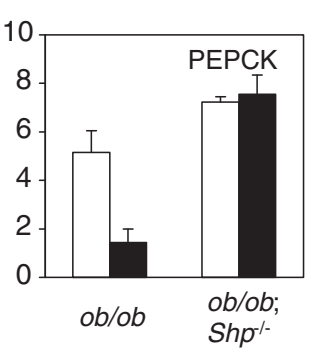

Figure $\mathbf{3}$ Expression of lipogenic genes was downregulated by SHP deficiency in ob/ob mice liver. Results in panels $\mathbf{A}$ and $\mathbf{B}$ are liver mRNA levels for control (open bars) and troglitazone-treated (filled bars) mice after 2 weeks of treatment. Data are expressed as relative fold change after normalized to $36 \mathrm{~B} 4$ and are mean \pm SEM ( $n=4-5$ per group). By two-way ANOVA, the genotype effect (ob/ob and ob/ob;Shp ${ }^{-1-}$ ) is significant $(P<0.05)$ for all except PPARY1 in panel $\mathbf{A}$. The treatment effect and genotype $\times$ treatment interaction is significant for CD36, aP2, FAS, ACC1 and PEPCK in panel $\mathbf{B}$.

relative to wild type, but only a 5 -fold increase in $o b /$ $o b ; S h p^{-1-}$ mice.

To further define the genes regulated by SHP in the $o b / o b$ liver and the mechanism of the decrease in 
hepatic triglyceride in $o b / o b ; S_{h}{ }^{-/-}$mice, mRNA from livers of control- and troglitazone-treated mice was analyzed (Figure 3B). mRNA levels of fatty acid translocase (CD36), fatty acid synthase (FAS), adipocyte fatty acid-binding protein (aP2), acetyl-CoA carboxylase 1 (ACC1) and stearoyl-CoA desaturase-1 (SCD-1) were lower in $o b / o b ; S h p^{-/-}$mice than in $o b / o b$ mice. Troglitazone treatment induced the expression of CD36, FAS, aP2 and ACC1 mRNA in $o b / o b$ mice, but not in $o b /$ $o b ; S h p^{-1-}$ mice. There was no difference between $o b / o b$ and $o b / o b ; S h p^{-1-}$ mice for expression of transcription factors regulating the lipogenic genes, such as SREBP-1c and C/EBP $\alpha$. The mRNA levels of genes associated with glucose homeostasis, such as phosphoenolpyruvate careboxykinase (PEPCK) for gluconeogenesis, were increased in ob/ob; $\mathrm{Shp}^{-1-}$ mice (Figure $3 \mathrm{~B}$ ), which may partly account for the high blood glucose levels in these double mutant mice (Figure 1A). The action of troglitazone to lower glucose levels in type 2 diabetics by decreasing gluconeogenesis in liver was observed in $o b / o b$ mice, but not in $o b / o b ; S h p^{-1-}$ mice.

In summary, expression of lipogenic genes was decreased by SHP deficiency in $o b / o b$ mice, which has also been observed in Western diet fed $\mathrm{Sh}^{-1-}$ mice [39]. Consistent with the low expression of hepatic PPAR $\gamma 2$ in $o b / o b ; \mathrm{Sh}^{-/-}$mice, functional response to PPAR $\gamma$ agonist, troglitazone, was impaired in $o b / o b ; S h p^{-1-}$ mice both in lipogenesis and gluconeogenesis.

\section{SHP deficiency affects TZD-responsive gene expression in adipose tissue of $o b / o b$ mice}

White adipose tissue has been thought to be the major site of TZD actions, as it is the only insulin-responsive tissue with high expression of PPAR $\gamma$ compared to liver and muscle [18]. Therefore, mRNA levels of genes responsive to TZDs in adipose tissue of control- and troglitazone-treated $o b / o b$ and $o b / o b ; S h p^{-1-}$ mice were analyzed by real-time quantitative PCR analysis (Figure 4). Adipose tissue from $o b / o b ; S h p^{-1-}$ mice showed an approximately $60 \%$ reduction in PPAR 2 expression, which was not as dramatic as the nearly $90 \%$ reduction in the liver (Figure 3A). CD36 and adiponectin expression was not different between genotypes, whereas resistin decreased $35 \%$ in $o b / o b ; S_{h p}{ }^{-1-}$ mice. Troglitazone induced the expression of PPAR 2 and CD36 to a lesser extent in $o b / o b ; S h p^{-1-}$ mice than that in $o b / o b$ mice, and failed to induce expression of adiponectin and resistin in $o b /$ $o b ; S_{h} p^{-1-}$ mice, demonstrating that SHP is required for full troglitazone responsiveness in adipose tissue.

\section{SHP upregulates PPARY2 expression in primary hepatocytes} To test the possibility that SHP might regulate PPAR 2 gene expression, the effects of SHP on the PPAR 2 gene were examined by infecting mouse primary hepatocytes

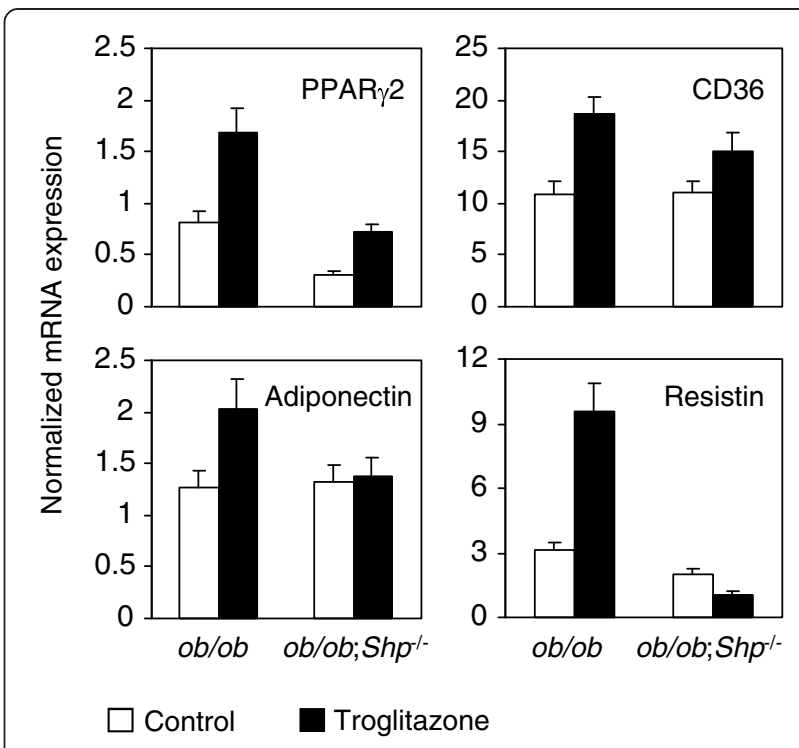

Figure 4 SHP deficiency affects TZD-responsive gene expression in adipose tissue of ob/ob mice. Results are adipose mRNA levels for control (open bars) and troglitazone-treated (filled bars) mice after 2 weeks of treatment. Data are expressed as relative fold change after normalized to 36B4 and are mean \pm SEM ( $n=4-5$ per group). By two-way ANOVA, the genotype and treatment effect is significant $(P<0.05)$ for PPARY2 and resistin (treatment effect for CD36, $P=0.06$ ).

The genotype $\times$ treatment interaction is significant only for resistin. By two-tailed $t$ test, $\mathrm{P}<0.05$ for differences in adiponectin expression between control and troglitazone-treated ob/ob mice.

with adenoviral vectors expressing SHP (Figure 5). Transduction of cultured hepatocytes with SHP adenovirus decreased expression of CYP 7A1 mRNA, a known SHP target gene, by 5.2 fold, while increasing PPAR $\gamma 2$ levels for 1.7 fold. These data indicate that SHP overexpression upregulates PPAR $\gamma 2$ expression in primary hepatocytes.

\section{Discussion}

The therapeutic use of TZD drugs in the treatment of insulin resistance and type 2 diabetes is now well established [3-5]. TZDs act by increasing insulin sensitivity. These drugs are high affinity ligands for the nuclear receptor PPAR $\gamma[9,10]$ and their antidiabetic effects are thought to be mediated through PPAR $\gamma$. Therefore, normal PPARY expression levels, especially in the insulinresponsive tissues, are critical for TZD actions. In this study, we found that SHP deficiency causes downregulation of PPAR 2 expression in liver and adipose tissue of $o b / o b$ mice, and these animals show diminished or abolished responsiveness to the TZD troglitazone. It is reported that mutations in SHP gene in humans are associated with insulin resistance and mild obesity [27]. Our data suggest that the diabetic syndromes of subjects with genetic mutations of SHP may not be improved by TZD treatment. This is the first in vivo evidence that 

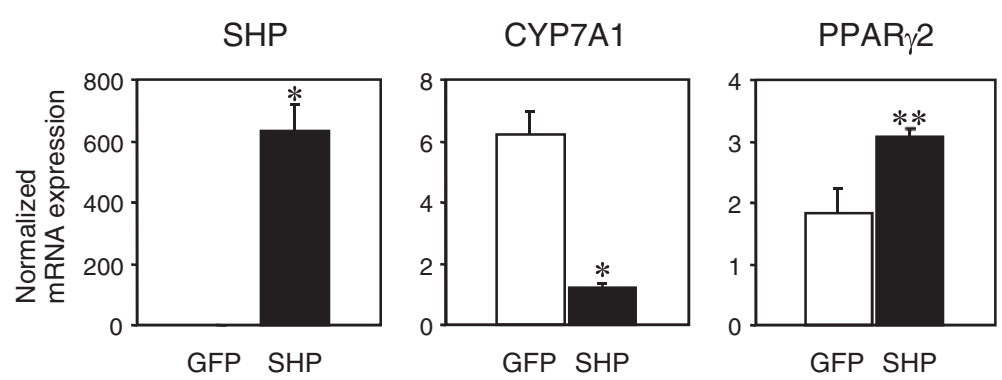

Figure 5 SHP increases PPARY2 expression in primary hepatocytes. Expression of SHP, CYP7A1 and PPARY2 in adenovirus-mediated GFP- or SHP-overexpressing hepatocytes by real-time quantitative PCR analysis. Hepatocytes were infected with green fluorescent protein (GFP) or SHP adenovirus as indicated. Data are expressed as relative fold change after normalized to $36 \mathrm{~B} 4$ and are $\mathrm{mean} \pm \mathrm{SEM}$ ( $\mathrm{n}=4-5 \mathrm{per}$ group). ${ }^{*} \mathrm{P}<0.001$, ${ }^{* *} \mathrm{P}<0.05$, compared with GFP-infected cells.

SHP mutation attenuates TZD actions, which makes SHP a possible pharmacogenetic determinant of TZD response.

The $o b / o b ; S h p^{-/-}$double mutant mice showed higher blood glucose levels than $o b / o b$ mice. This may be attributed to abnormal glucose homeostasis in two tissues: skeletal muscle and liver, which have the greatest direct impact on plasma glucose levels. Whereas no difference was observed between $o b / o b$ and $o b / o b ; S h p^{-/-}$mice in gene expression of glucose oxidation and glycogen synthesis in muscle (data not shown), hepatic PEPCK mRNA expression is enhanced in $o b / o b ; S h p^{-1-}$ mice compared to $o b / o b$ mice, suggesting that increased gluconeogenesis may contribute to elevated glucose levels. Moreover, the low insulin levels of $o b / o b ; S h p^{-/-}$mice may indicate that pancreatic $\beta$ cells fail to appropriately compensate for insulin resistance by increasing insulin secretion. It has been shown that independent of PPAR $\gamma$ activation, SHP positively regulates glucose-stimulated insulin secretion (GSIS) in $\beta$ cells [40], which might be impaired in $o b / o b ; S h p^{-/-}$mice.

The observation that $o b / o b ; S h p^{-1-}$ mice exhibit worse hyperglycemia and glucose intolerance than $o b / o b$ mice contrasts with our previous report [36]. In that study, glucose and insulin levels were comparable in both genotypes and loss of SHP was associated with improved insulin sensitivity. One possible explanation is that the age and gender of the mice in the two reports are not exactly the same. The current studies focused solely on male mice at the age of 10 weeks, or older after 2 weeks of control or troglitazone treatment, whereas the prior study used age- and sex-matched groups of younger 8 week old mice. The age of the $o b / o b$ mice may be particularly important since blood glucose rises in this time period before reaching a peak during 3-5 months of age. Thus, it is possible that earlier beneficial effects of the loss of SHP are not evident in these somewhat older mice. Consistent with this, we have observed very similar negative effects of the loss of SHP in long term studies of wild type and $S h p^{-1-}$ mice fed a Western diet [39].

The loss of TZD responsiveness in the $o b / o b ; S h p^{-/-}$ mice is presumably a consequence of decreased PPAR $\gamma$ expression. PPAR 1 expression in adipose tissue, liver and muscle is not changed between genotypes, and PPAR 2 expression in muscle is unaffected (Figure 3A and data not shown). Thus, we conclude that loss of SHP primarily affects PPAR $\gamma 2$ expression, which is the dominant isoform in both adipose tissue and fatty liver [41]. Although the effect on PPAR 22 expression was strongest in the liver, a major SHP expressing tissue, decreased hepatic PPAR 2 cannot account for the loss of antidiabetic effects of TZDs, since rosiglitazone improved glucose homeostasis in liver-specific PPAR $\gamma$ knockout mice in the $o b / o b$ background [18]. Although SHP is expressed at only low levels in adipose tissue $[33,38]$, white adipose is the primary target of TZD actions and PPAR 2 expression was significantly decreased in $o b / o b ; S h p^{-/-}$adipose tissue. Consistent with this, the induction of CD36 by troglitazone was decreased, and the response of both adiponectin and resistin was lost in the $o b / o b ; S h p^{-/-}$adipose tissue. Adiponectin promotes fatty acid oxidation and insulin sensitivity in muscle and liver, and the antidiabetic effects of a low dose of pioglitazone were lost in mice in which adiponectin deficiency was introduced into the $o b / o b$ background [42]. Thus, the absence of its induction is likely a major factor in the attenuated effects of troglitazone in the $o b / o b ; S h p^{-/-}$ mice. In contrast, elevated resistin has been proposed to increase insulin resistance, and the repression of resistin expression in normal mice by PPAR $\gamma$ agonists is thought to enhance insulin sensitivity $[43,44]$. Thus, the inductive effect of resistin by troglitazone in the $o b / o b$ mice and the loss of this response in the $o b / o b ; S h^{-1-}$ mice seems inconsistent with the known resistin action. Similar inductive effects of resistin by PPAR $\gamma$ activation have previously been described in both $o b / o b$ mice and Zucker 
diabetic fatty rats [45], but this was not observed in another study [42]. The basis for these discrepant mRNA expression results, and also a substantial disconnect between resistin adipose mRNA and serum protein levels in $o b / o b$ mice [46], remains unresolved.

SHP is involved in the development of fatty liver by regulating hepatic PPAR $\gamma 2$ and lipogenic genes. The increase in PPAR 2 appears to be a general property of steatotic liver in diet-induced and genetic obese models [18-20,47,48]. Overexpression of PPARY in a hepatic cell line leads to marked lipid accumulation [49], as does overexpression in PPAR $\alpha$ null livers [50]. Thus, SHP deficiency reduced the elevated levels of PPAR $\gamma 2$ and lipogenic genes in $o b / o b$ liver, resulting in the improvement of fatty liver. Additional effects on other pathways may also contribute to the decreased triglyceride accumulation [36].

Recent studies have started to shed light on the molecular basis for the transcriptional regulation of PPAR $\gamma$ by SHP. Renga et al. described that FXR binds to the PPAR $\gamma$ promoter and activates its transcription via the recruitment of SHP in hepatic stellate cells [51]. Whereas Kim et al. identified a novel transcriptional cascade linking RAR/SHP signals with PPAR 2 expression through hairy and enhancer of split 6 (Hes6) in hepatocytes [52]. This transcriptional regulatory pathway controls hepatic lipid metabolism and provides a potential therapeutic entry point for NAFLD. These studies indicate that SHP appears to upregulate PPAR $\gamma$ expression by diverse mechanisms in different cell types.

\section{Conclusions}

In summary, our results demonstrate that the antidiabetic and hypolipidemic actions of TZDs require the presence of SHP, likely due to the downregulation of PPAR 2 expression in the adipose tissue and liver of $o b /$ $o b ; S h^{-1-}$ mice. Thus, genetic or pharmacologic modulation of SHP activity could alter the efficacy of TZD antidiabetic actions.

\begin{abstract}
Abbreviations
ACC1: Acetyl-CoA carboxylase; aP2: Adipocyte fatty acid-binding protein; CD36: Fatty acid translocase; C/EBPa: CCAAT/enhancer binding protein alpha; FAS: Fatty acid synthase; FXR: Farnesoid X receptor; GFP: Green fluorescent protein; FFA: Free fatty acid; NAFLD: Non-alcoholic fatty liver disease; NASH: Non-alcoholic steatohepatitis; PEPCK: Phosphoenolpyruvate careboxykinase; PPARY: Peroxisome proliferator-activated receptor gamma; RAR: Retinoic acid receptor; SCD-1: Stearoyl-CoA desaturase-1; SHP: Small heterodimer partner; SREBP-1c: Sterol regulatory element-binding protein 1c; TG: Triglyceride; TZDs: Thiazolidinediones; WT: Wild type.
\end{abstract}

\section{Competing interests}

The authors declare that they have no competing interests.

\section{Authors' contributions}

HTT and DDM conceived and designed experiments, interpreted data and drafted the paper. YJP and YKL participated in the design of the study and contributed to conception. All authors read and approved the final manuscript

\section{Acknowledgements}

We are grateful to J. Liu for assistance with mouse breeding, to Dr. V. K. Yechoor and Dr. B. Chang for assistance in generating adenovirus stocks, and to Drs. J. Lee, K. Ma, M. L. Ricketts, S. A. Johnson and S. Anakk for support and helpful discussions. This work was supported by National Institutes of Health grants R01 DK068804 and U19DK62434 to D.D.M.

\section{Author details}

'Department of Molecular and Cellular Biology, Baylor College of Medicine, One Baylor Plaza, Houston, Texas, USA. ${ }^{2} 300$ Gumi-dong, Bundang-gu, Department of Internal Medicine, Seoul National University Bundang Hospital, Seongnam-si, Kyeonggi-do, South Korea. ${ }^{3}$ Department of Integrative Medical Sciences, Northeast Ohio Medical University, Rootstown, OH, USA.

Received: 22 January 2015 Accepted: 30 March 2015

Published online: 08 May 2015

\section{References}

1. Kopelman PG. Obesity as a medical problem. Nature. 2000;404(6778):635-43.

2. Haslam DW, James WP. Obesity Lancet. 2005;366(9492):1197-209.

3. Soccio RE, Chen ER, Lazar MA. Thiazolidinediones and the promise of insulin sensitization in type 2 diabetes. Cell Metab. 2014;20(4):573-91. doi:10.1016/j.cmet.2014.08.005.

4. Saltiel AR, Olefsky JM. Thiazolidinediones in the treatment of insulin resistance and type II diabetes. Diabetes. 1996;45(12):1661-9.

5. Olefsky JM. Treatment of insulin resistance with peroxisome proliferator-activated receptor gamma agonists. J Clin Invest. 2000;106(4):467-72.

6. Maggs DG, Buchanan TA, Burant CF, Cline G, Gumbiner B, Hsueh WA, et al. Metabolic effects of troglitazone monotherapy in type 2 diabetes mellitus. A randomized, double-blind, placebo-controlled trial. Ann Intern Med. 1998;128(3):176-85.

7. Fujiwara T, Wada M, Fukuda K, Fukami M, Yoshioka S, Yoshioka T, et al. Characterization of CS-045, a new oral antidiabetic agent, II. Effects on glycemic control and pancreatic islet structure at a late stage of the diabetic syndrome in C57BL/KsJ-db/db mice. Metabolism. 1991;40(11):1213-8.

8. Fujiwara T, Yoshioka S, Yoshioka T, Ushiyama I, Horikoshi H. Characterization of new oral antidiabetic agent CS-045. Studies in KK and ob/ob mice and Zucker fatty rats. Diabetes. 1988;37(11):1549-58.

9. Lehmann JM, Moore LB, Smith-Oliver TA, Wilkison WO, Willson TM, Kliewer SA. An antidiabetic thiazolidinedione is a high affinity ligand for peroxisome proliferator-activated receptor gamma (PPAR gamma). J Biol Chem. 1995;270(22):12953-6.

10. Rangwala SM, Lazar MA. Peroxisome proliferator-activated receptor gamma in diabetes and metabolism. Trends Pharmacol Sci. 2004;25(6):331-6.

11. Tontonoz P, Hu E, Spiegelman BM. Stimulation of adipogenesis in fibroblasts by PPAR gamma 2, a lipid- activated transcription factor. Cell. 1994;79(7):1147-56.

12. Mueller E, Drori S, Aiyer A, Yie J, Sarraf P, Chen H, et al. Genetic analysis of adipogenesis through peroxisome proliferator-activated receptor gamma isoforms. J Biol Chem. 2002;277(44):41925-30.

13. Vidal-Puig AJ, Considine RV, Jimenez-Linan M, Werman A, Pories WJ, Caro $J F$, et al. Peroxisome proliferator-activated receptor gene expression in human tissues. Effects of obesity, weight loss, and regulation by insulin and glucocorticoids. J Clin Invest. 1997;99(10):2416-22.

14. Zhang J, Fu M, Cui T, Xiong C, Xu K, Zhong W, et al. Selective disruption of PPARgamma 2 impairs the development of adipose tissue and insulin sensitivity. Proc Natl Acad Sci U S A. 2004;101(29):10703-8.

15. Norris AW, Chen L, Fisher SJ, Szanto I, Ristow M, Jozsi AC, et al. Muscle-specific PPARgamma-deficient mice develop increased adiposity and insulin resistance but respond to thiazolidinediones. J Clin Invest. 2003;112(4):608-18.

16. He W, Barak Y, Hevener A, Olson P, Liao D, Le J, et al. Adipose-specific peroxisome proliferator-activated receptor gamma knockout causes insulin resistance in fat and liver but not in muscle. Proc Natl Acad Sci U S A. 2003;100(26):15712-7.

17. Hevener AL, Olefsky JM, Reichart D, Nguyen MT, Bandyopadyhay G, Leung $H Y$, et al. Macrophage PPAR gamma is required for normal skeletal muscle and hepatic insulin sensitivity and full antidiabetic effects of thiazolidinediones. J Clin Invest. 2007;117(6):1658-69.

18. Matsusue K, Haluzik M, Lambert G, Yim SH, Gavrilova O, Ward JM, et al. Liver-specific disruption of PPARgamma in leptin-deficient mice improves 
fatty liver but aggravates diabetic phenotypes. J Clin Invest. 2003;111(5):737-47.

19. Chao L, Marcus-Samuels B, Mason MM, Moitra J, Vinson C, Arioglu E, et al. Adipose tissue is required for the antidiabetic, but not for the hypolipidemic, effect of thiazolidinediones. J Clin Invest. 2000;106(10):1221-8.

20. Memon RA, Tecott LH, Nonogaki K, Beigneux A, Moser AH, Grunfeld C, et al. Up-regulation of peroxisome proliferator-activated receptors (PPAR-alpha) and PPAR-gamma messenger ribonucleic acid expression in the liver in murine obesity: troglitazone induces expression of PPAR-gammaresponsive adipose tissue-specific genes in the liver of obese diabetic mice. Endocrinology. 2000;141(11):4021-31.

21. Westerbacka J, Kolak M, Kiviluoto T, Arkkila P, Siren J, Hamsten A, et al. Genes involved in fatty acid partitioning and binding, lipolysis, monocyte/ macrophage recruitment, and inflammation are overexpressed in the human fatty liver of insulin-resistant subjects. Diabetes. 2007:56(11):2759-65.

22. Neuschwander-Tetri BA, Brunt EM, Wehmeier KR, Oliver D, Bacon BR. Improved nonalcoholic steatohepatitis after 48 weeks of treatment with the PPAR-gamma ligand rosiglitazone. Hepatology. 2003;38(4):1008-17.

23. Belfort R, Harrison SA, Brown K, Darland C, Finch J, Hardies J, et al. A placebo-controlled trial of pioglitazone in subjects with nonalcoholic steatohepatitis. N Engl J Med. 2006;355(22):2297-307.

24. Nishigori $\mathrm{H}$, Tomura $\mathrm{H}$, Tonooka N, Kanamori M, Yamada S, Sho K, et al. Mutations in the small heterodimer partner gene are associated with mild obesity in Japanese subjects. Proc Natl Acad Sci U S A. 2001;98(2):575-80.

25. Mitchell SM, Weedon MN, Owen KR, Shields B, Wilkins-Wall B, Walker M, et al. Genetic variation in the small heterodimer partner gene and young-onset type 2 diabetes, obesity, and birth weight in U.K. subjects. Diabetes. 2003;52(5):1276-9.

26. Hung CC, Farooqi IS, Ong K, Luan J, Keogh JM, Pembrey M, et al. Contribution of variants in the small heterodimer partner gene to birthweight, adiposity, and insulin levels: mutational analysis and association studies in multiple populations. Diabetes. 2003;52(5):1288-91.

27. Enya M, Horikawa Y, Kuroda E, Yonemaru K, Tonooka N, Tomura H, et al. Mutations in the small heterodimer partner gene increase morbidity risk in Japanese type 2 diabetes patients. Hum Mutat. 2008;29(11):E271-7. doi:10.1002/humu.20865.

28. Seol W, Choi HS, Moore DD. An orphan nuclear hormone receptor that lacks a DNA binding domain and heterodimerizes with other receptors. Science. 1996;272(5266):1336-9.

29. Seol W, Chung M, Moore DD. Novel receptor interaction and repression domains in the orphan receptor SHP. Mol Cell Biol. 1997;17(12):7126-31.

30. Johansson L, Thomsen JS, Damdimopoulos AE, Spyrou G, Gustafsson J, Treuter E. The orphan nuclear receptor SHP inhibits agonist-dependent transcriptional activity of estrogen receptors ERalpha and ERbeta. J Biol Chem. 1999;274(1):345-53.

31. Lee YK, Dell H, Dowhan DH, Hadzopoulou-Cladaras M, Moore DD. The orphan nuclear receptor SHP inhibits hepatocyte nuclear factor 4 and retinoid $X$ receptor transactivation: two mechanisms for repression. Mol Cell Biol. 2000;20(1):187-95.

32. Lee YK, Moore DD. Dual mechanisms for repression of the monomeric orphan receptor liver receptor homologous protein-1 by the orphan small heterodimer partner. J Biol Chem. 2002;277(4):2463-7.

33. Nishizawa H, Yamagata K, Shimomura I, Takahashi M, Kuriyama H, Kishida K, et al. Small heterodimer partner, an orphan nuclear receptor, augments peroxisome proliferator-activated receptor gamma transactivation. J Biol Chem. 2002;277(2):1586-92.

34. Boulias K, Katrakili N, Bamberg K, Underhill P, Greenfield A, Talianidis I. Regulation of hepatic metabolic pathways by the orphan nuclear receptor SHP. Embo J. 2005;24(14):2624-33.

35. Wang L, Lee Y-K, Bundman D, Han Y, Thevananther S, Kim C-S, et al. Redundant Pathways for Negative Feedback Regulation of Bile Acid Production. Developmental Cell. 2002;2:723-1.

36. Huang J, labal J, Saha PK, Liu J, Chan L, Hussain MM, et al. Molecular characterization of the role of orphan receptor small heterodimer partner in development of fatty liver. Hepatology. 2007:46(1):147-57.

37. Mao J, DeMayo FJ, Li H, Abu-Elheiga L, Gu Z, Shaikenov TE, et al. Liver-specific deletion of acetyl-CoA carboxylase 1 reduces hepatic triglyceride accumulation without affecting glucose homeostasis. Proc Natl Acad Sci U S A. 2006;103(22):8552-7.
38. Wang L, Liu J, Saha P, Huang J, Chan L, Spiegelman B, et al. The orphan nuclear receptor SHP regulates PGC-1alpha expression and energy production in brown adipocytes. Cell Metab. 2005;2(4):227-38.

39. Park YJ, Kim SC, Kim J, Anakk S, Lee JM, Tseng HT, et al. Dissociation of diabetes and obesity in mice lacking orphan nuclear receptor small heterodimer partner. J Lipid Res. 2011;52(12):2234-44. doi:10.1194/Jlir.M016048.

40. Suh YH, Kim SY, Lee HY, Jang BC, Bae JH, Sohn JN, et al. Overexpression of short heterodimer partner recovers impaired glucose-stimulated insulin secretion of pancreatic beta-cells overexpressing UCP2. J Endocrinol. 2004;183(1):133-44.

41. Edvardsson U, Bergstrom M, Alexandersson M, Bamberg K, Ljung B, Dahllof B. Rosiglitazone (BRL49653), a PPARgamma-selective agonist, causes peroxisome proliferator-like liver effects in obese mice. J Lipid Res. 1999;40(7):1177-84.

42. Kubota N, Terauchi Y, Kubota T, Kumagai H, Itoh S, Satoh H, et al. Pioglitazone ameliorates insulin resistance and diabetes by both adiponectin-dependent and -independent pathways. J Biol Chem. 2006;281(13):8748-55.

43. Moore GB, Chapman H, Holder JC, Lister CA, Piercy V, Smith SA, et al. Differential regulation of adipocytokine mRNAs by rosiglitazone in $\mathrm{db} / \mathrm{db}$ mice. Biochem Biophys Res Commun. 2001;286(4):735-41.

44. Steppan CM, Bailey ST, Bhat S, Brown EJ, Banerjee RR, Wright CM, et al. The hormone resistin links obesity to diabetes. Nature. 2001;409(6818):307-12.

45. Way JM, Gorgun CZ, Tong Q, Uysal KT, Brown KK, Harrington WW, et al. Adipose tissue resistin expression is severely suppressed in obesity and stimulated by peroxisome proliferator-activated receptor gamma agonists. J Biol Chem. 2001;276(28):25651-3.

46. Rajala MW, Qi Y, Patel HR, Takahashi N, Banerjee R, Pajvani UB, et al. Regulation of resistin expression and circulating levels in obesity, diabetes, and fasting. Diabetes. 2004;53(7):1671-9.

47. Gavrilova O, Haluzik M, Matsusue K, Cutson JJ, Johnson L, Dietz KR, et al. Liver peroxisome proliferator-activated receptor gamma contributes to hepatic steatosis, triglyceride clearance, and regulation of body fat mass. J Biol Chem. 2003:278(36):34268-76.

48. Zhang YL, Hernandez-Ono A, Siri P, Weisberg S, Conlon D, Graham MJ, et al. Aberrant hepatic expression of PPARgamma2 stimulates hepatic lipogenesis in a mouse model of obesity, insulin resistance, dyslipidemia, and hepatic steatosis. J Biol Chem. 2006;281(49):37603-15.

49. Schadinger SE, Bucher NL, Schreiber BM, Farmer SR. PPARgamma2 regulates lipogenesis and lipid accumulation in steatotic hepatocytes. Am J Physiol Endocrinol Metab. 2005;288(6):E1195-205.

50. Yu S, Matsusue K, Kashireddy P, Cao WQ, Yeldandi V, Yeldandi AV, et al. Adipocyte-specific gene expression and adipogenic steatosis in the mouse liver due to peroxisome proliferator-activated receptor gammal (PPARgamma1) overexpression. J Biol Chem. 2003;278(1):498-505.

51. Renga B, Mencarelli A, Migliorati M, Cipriani S, D'Amore C, Distrutti E, et al. SHP-dependent and -independent induction of peroxisome proliferator-activated receptor-gamma by the bile acid sensor farnesoid $X$ receptor counter-regulates the pro-inflammatory phenotype of liver myofibroblasts. Inflamm Res. 2011;60(6):577-87. doi:10.1007/s00011-010-0306-1.

52. Kim SC, Kim CK, Axe D, Cook A, Lee M, Li T, et al. All-trans-retinoic acid ameliorates hepatic steatosis in mice by a novel transcriptional cascade. Hepatology. 2014;59(5):1750-60. doi:10.1002/hep.26699.

\section{Submit your next manuscript to BioMed Central and take full advantage of:}

- Convenient online submission

- Thorough peer review

- No space constraints or color figure charges

- Immediate publication on acceptance

- Inclusion in PubMed, CAS, Scopus and Google Scholar

- Research which is freely available for redistribution 